\title{
DESCARTE F CONSUMO: NARRATIVAS PARTICIPATIVAS VISUAIS DE CRIANÇAS E ADOLESCENTES RESIDENTES NO JARDIM GRAMACHO
}

\author{
Daniel Meirinho \\ Departamento de Comunicação Social, Programa de Pós-Graduação em Estu- \\ dos da Mídia, Universidade Federal do Rio Grande do Norte, Brasil
}

\begin{abstract}
Resumo
O artigo convida-nos a refletir sobre o modo como um grupo de 16 crianças e jovens, de quatro a 15 anos, moradores do antigo aterro sanitário do Jardim Gramacho, no Rio de Janeiro, atua como agentes narradores das suas próprias histórias. A partir da análise das fotografias produzidas pelo grupo de participantes, o trabalho propõe-se perceber como representam visualmente as práticas sociais de consumo contemporâneo e o ambiente de descarte em que vivem. A fotografia participativa é a ferramenta de construção e reflexão crítica de significados que possibilita uma percepção crítica em torno do consumo, mas não da aquisição de bens como brinquedos, ambientes de brincadeiras e outros objetos através do método photovoice. A pesquisa se integra ao projeto de intervenção social "Olhares do Gramacho" que desenvolveu em novembro de 2018 um conjunto de oficinas e culminou numa exposição fotográfica no fim da ação.
\end{abstract}

Palavras-chave

fotografia participativa; infância; aterro sanitário; consumo; photovoice

\section{DISPOSAL AND CONSUMPTION: VISUAL PARTICIPATORY NARRATIVES OF CHILDREN AND ADOLESCENTS LIVING IN JARDIM GRAMACHO}

\begin{abstract}
This article invites us to realize how a group of 16 children and young people, from four to 15 years, residents of the old landfill of Jardim Gramacho, in Rio de Janeiro, act as narrators of their own stories. Based on the analysis of the photographs produced by the group of participants, the article aims to understand how they visually represent contemporary social consumption practices and the disposal environment in which they live. The participatory photography is a tool for the construction and critical reflection of meanings that involve a critical perception around consumption, but not the acquisition of goods such as toys, play environments and other objects, through the photovoice method. The research is part of the project of social intervention "Olhares do Gramacho" that developed in November 2018 a set of workshops which culminated in a photographic exhibition at the end of the action.
\end{abstract}

\section{KEYWORDS}

participatory photography; childhood; sanitary landfill; consumption; photovoice 


\section{INTRODUÇÃo}

Desde sua invenção até sua alargada acessibilidade, a fotografia tem sido tratada popularmente e percebida umas vezes como uma janela que observa o mundo tal qual ele se apresenta e outras vezes como um espelho que refrata uma realidade (Barthes, 1984; Baudrillard, 1995; Sontag, 1986). Muitos debates abordam a sua veracidade, sendo a fotografia compreendida como um moderno formato de enquadrar as diversas percepções do mundo real (Baudrillard, 1995). Contudo, esta "produção de realidade" cria um universo de simulações a partir de experiências visuais de contextos periféricos não hegemônicos que reproduzem narrativas e representações a partir dos seus repertórios culturais, econômicos e sociais.

A fotografia ao longo dos anos se torna um referencial por vezes repleto de estereótipos que ativam memórias cristalizadas a partir do olhar estrangeiro que localiza e posiciona holofotes sobre o que deve fazer parte da agenda de preocupações globais e locais. Para Mark Sealy (2019), a fotografia se tornou um referencial de como algumas culturas veem os "outros", em um trabalho de arquivamento da memória cultural, que por vezes desempenha um papel de representação ideológica violenta de alguns povos e grupos sociais. Estas imagens são repletas de estereótipos que ativam memórias cristalizadas em uma relação de poder entre "observador e observado" que localiza e posiciona holofotes sobre aqueles que devem fazer parte da agenda de preocupações globais, ao mesmo tempo que projeta "uma imagem inferior ou humilhante sobre o outro que distorce e oprime, na medida em que a imagem é internalizada" (Taylor, 1994, p. 36).

Partimos neste artigo da seguinte questão central: como um grupo de crianças e adolescentes, residentes em um antigo aterro sanitário no Rio de Janeiro, reflete a partir de suas fotografias o consumo na perspectiva do descarte e não da aquisição de objetos e bens? A proposta parte de um projeto de investigação-ação participativa e de intervenção social chamado "Olhares do Gramacho", que utilizou a imagem fotográfica como instrumento para encontros e diálogos com um grupo de 16 crianças e adolescentes, com idades entre quatro a 15 anos. Todos os participantes residiam na comunidade Quatro Rodas, inserida onde esteve localizado por quase 40 anos o maior "lixão" da América Latina: o Aterro Metropolitano de Jardim Gramacho (AMJG), no Rio de Janeiro, Brasil.

Durante seis dias, em novembro de 2018 , este grupo de crianças e adolescentes atuaram como agentes narradores de suas próprias realidades, sendo as fotografias produzidas pelos participantes uma ferramenta de reflexão crítica em torno da cultura contemporânea do descarte social e humano e de uma identidade deteriorada através da metodologia participativa visual photovoice (Wang \& Burris, 1997). A proposta de uma metodologia que toma crianças e adolescentes como sujeitos da pesquisa apresenta um modelo não tão comum de estudar a infância, particularmente na comunicação em que a fotografia é percebida como uma tecnologia de comunicação e expressão. $O$ método photovoice (Wang \& Burris, 1997) insere no processo investigativo atividades de base comunitária e participativa que promovem competências visuais de identificação, representação e diálogo em torno de temáticas específicas com o grupo social, através de suas representações fotográficas. 
$\mathrm{O}$ artigo problematiza como a imagem pode ser um referencial de ações reflexivas coletivas para um grupo de crianças e adolescentes, a partir da produção desta visualidade em torno das suas perspectivas e experiências pessoais com o descarte e as questões de consumo (Marshall \& Shepard, 2006). E ainda como crianças e adolescentes residentes em uma área de aterro sanitário podem ativamente contribuir para uma representação imagética desarmônica e oposta à que é apresentada pela mídia sobre o debate sobre lixo. Se Bauman (2005) argumenta que "a sobrevivência da forma de vida moderna depende da destreza e da proficiência na remoção do lixo" (p. 39), a reintrodução dos bens de consumo e produtos da cultura de descarte são percebidos pelas crianças e adolescentes a partir de uma lógica de exclusão e inclusão. Ao mesmo tempo, esse grupo social é uma poderosa peça da engrenagem mediática e publicitária do sistema de consumo (Souza, 2016). A apropriação de bens materiais pode ser percebida por um ciclo de reutilização das coisas e não pela normativa de obsolescência que propicia comportamentos obsessivos de aquisição de novos objetos, da sociedade de consumo.

A imagem fotográfica foi a ferramenta que possibilitou debates sobre os interesses e regimes de visibilidade do grupo de crianças e adolescentes participantes com enfoque na temática em torno do consumo e do descarte contemporâneo, já que vivem em um ambiente que recebe todos os resíduos sólidos e lixo reciclável de uma das mais populosas regiões metropolitanas do Brasil. Câmaras fotográficas digitais estiveram em posse deste grupo de crianças e adolescentes durante uma semana. O objetivo foi perceber como o registro e as representações visuais do que compreendem como lixo e descarte contrastam ou se assemelham com a representação mediática do espaço em que vivem e como são os ajustamentos e as complexas questões de convívio com o lixo e despejo ilegal de produtos e objetos.

O projeto "Olhares do Gramacho" teve em seus seis dias de oficinas a produção de 3.912 fotografias, realizadas pelas 16 crianças e adolescentes residentes na comunidade Quatro Rodas, do Jardim Gramacho. As imagens retratam, além do tema do descarte, as relações entre os participantes, seus familiares e a comunidade, com muitas imagens de espaços coletivos (ruas, estação de tratamento de água, campo de futebol), ambientes privados (associações de moradores e catadores), pessoas do bairro e as relações afetivas com seus amigos e animais de estimação, bem como objetos e lixo. Houve um grande percentual de imagens de flores dos "jardins" pessoais das casas e das organizações, com uma alusão direta ao nome do bairro. Para o recorte analítico deste artigo são analisadas as imagens de objetos descartados que são reutilizados e os espaços lúdicos de brincadeiras em torno da lógica do consumo de (re) apropriação com base na relação dos participantes enquanto receptores de depósito de uma sociedade de excessos do consumismo contemporâneo (Uglione, 2018) e suas relações de autoestima e afetividade com estes materiais.

\section{A INVESTIGAÇÃo PARTICIPATIVA VISUAL COM CRIANÇAS E ADOLESCENTES}

Devido à crescente ênfase nos direitos da criança e do adolescente, a participação das crianças em estudos sobre questões sociais tem vindo a tornar-se uma tendência, 
no âmbito da importância dada a ouvir suas perspectivas e compreender suas experiências de vida. O interesse pela participação de crianças e jovens na investigação vem aumentando mais a cada ano e tem salientado a importância de ouvir suas perspectivas e entender suas vidas e experiências (Clark, 2007; Green \& Hogan, 2005; Sinclair, 2004). O interesse acadêmico em buscar as perspectivas das crianças na investigação (Lewis $\&$ Lindsay, 2000), dentro da estrutura dos direitos da criança, passa a reconhecer como valiosos os pensamentos e experiências das crianças e adolescentes.

A Convenção das Nações Unidas sobre os direitos da criança, adotada pela Assembleia Geral da ONU em 20 de novembro de 1989, veio estimular ainda mais o desenvolvimento de estratégias de investigação ajustadas aos direitos da criança (Lundy \& McEvoy, 2012). A Convenção estabelece direitos que devem ser alcançados para que crianças e adolescentes alcancem seu pleno potencial e exige que políticas e serviços relativos às crianças respondam à sua ampla gama de necessidades e capacidades (Lundy \& McEvoy, 2012). Assim, as crianças passam a ter o direito de expressar seus pontos de vista nos processos de tomada de decisão, conforme o Artigo 12 que afirma:

Artigo 12. Os Estados Partes assegurarão à criança que estiver capacitada a formular seus próprios juízos, o direito de expressar suas opiniões livremente sobre todos os assuntos relacionados com a criança, levando-se devidamente em consideração essas opiniões, em função da idade e maturidade da criança. (Decreto $n^{\circ}$ 99.710)

Esse lugar e direito de participar ativamente de investigações relacionadas a assuntos relacionados a elas reflete "sobre o lugar que as crianças ocupam e como entram nessa disputa de sentidos" (Pereira, Gomes \& Silva, 2018, p. 762). O direito à participação estabelecido pela Convenção muda o foco da realização de investigações sobre crianças para o foco em investigações com crianças.

A investigação-ação participativa com crianças e jovens aplicada neste artigo possui uma história recente e vem crescendo nos últimos anos em diversos contextos socioculturais a partir das chamadas de investigação-ação participativa (Khanlou \& Peter, 2005). Este movimento de pesquisa desafia o sistema de vigilância e controle de conhecimento por meio da investigação: "quanto mais os participantes procuram o controle ativo das agendas da investigação, mais poderosos estes agentes se estabelecem" (Khanlou \& Peter, 2005, p. 2339).

Ao buscar as perspectivas visuais de crianças e adolescentes, o projeto "Olhares do Gramacho" reconhece que este não é um grupo hegemónico, mas que cada um e cada uma tem seu próprio conjunto de características e experiências, que os tornam únicos (Lewis \& Lindsay, 2000). Os métodos visuais participativos foram escolhidos nesta investigação enquanto uma ferramenta útil no envolvimento do grupo de crianças e adolescentes do Jardim Gramacho, como um convite de que registrassem fotograficamente suas vidas cotidianas. A fotografia passaria a ser discutida em um contexto de compartilhamento de narrativas críticas em torno dos regimes de visibilidade e descarte de objetos e no local onde vivem (Wang \& Burris, 1997). O método photovoice foi a 
abordagem metodológica que forneceu a possibilidade de se expressarem visualmente, utilizando um olhar ativo para definir questões que os afetam (Lust, 2013; Woodlrych, 2004), refletindo criticamente em torno das vozes e representações hegemónicas que, na grande maioria das vezes, não os constituem identitariamente.

Desenvolvido no início da década de 90 do século passado pela professora e investigadora da Escola de Saúde Pública da Universidade de Michigan, Caroline Wang, e pela investigadora associada da Escola de Estudos Orientais e Africanos da Universidade de Londres, Mary Ann Burris, a abordagem metodológica photovoice se propõe a inserir no processo investigativo atividades de base comunitária com o intuito de "identificar, representar e reforçar os recursos das suas comunidades através de técnicas e representações fotográficas" (Wang \& Burris, 1997, p. 369). A fotografia passa a ser um suporte e ferramenta de trabalho "que serve como instrumento para criar relações, informar e organizar indivíduos da comunidade, permitindo-lhes dar prioridade às suas preocupações e discutir seus problemas e soluções coletivamente, através dos enquadramentos visuais" (Wang \& Burris, 1997, p. 370).

Apesar da proposta metodológica ter sido criada no campo dos estudos da saúde pública e coletiva, o método tem sido uma reconhecida ferramenta em investigações com crianças e adolescentes (Ewald, 2001; Mcintyre \& Thusi, 2003; Spielman, 2001; Meirinho, 2016; Wilson, Dasho, Martin, Wallerstein, Wang \& Minkler, 2007). A fotografia participativa (Palibroda, Krieg, Murdock \& Havelock, 2009) foi um instrumento estratégico e precioso pela possibilidade de proporcionar às crianças e adolescentes do Jardim Gramacho a oportunidade de discutir sua comunidade e seus hábitos a partir das suas representações visuais. Neste caso, o método visual serviu-nos como meio atrativo para envolver ativamente os participantes no processo de pesquisa, bem como um instrumento analítico.

\section{O JARDIM GRAMACHO ENQUANTO CONTEXTO DE INTERVENÇÃO SOCIAL INVESTIGATIVA}

Localizado na região metropolitana do Rio de Janeiro, por quase 40 anos o Jardim Gramacho abrigou o maior aterro sanitário da América Latina (Cárcamo, De Oliveira \& Da Cunha, 2018). Ocupando uma área de 1,3 milhões de metros quadrados (Bastos, 2007), ficou conhecido mundialmente através dos filmes Estamira (Padro, 2005), o documentário Lixo extraordinário (Walker, Jardim \& Harley, 2010), e também do filme Trash - a esperança vem do Lixo (Daldry, 2014). Estes filmes projetaram o bairro e as precárias condições humanas nos conhecidos lixões. $O$ aterro teve a sua inauguração no final da década de 70 e foi desativado em junho de 2012, deixando mais de mil famílias de ex-catadores, incluindo diversas crianças e adolescentes vivendo no local. Durante 34 anos de funcionamento chegou a receber um volume de lixo de oito mil toneladas por dia (IBASE - Instituto Brasileiro de Análises Sociais e Econômicas, 2005), criando uma "montanha" de resíduos sólidos que ultrapassou os 40 metros de altura.

'A designação photovoice é compreendida como um acrónimo para voicing our individual and collective experience (expressando nossa experiência individual e coletiva, em Português). 
O Jardim Gramacho está localizado na baía de Guanabara e esta faz parte do município de Duque de Caxias, que ocupa uma área da região metropolitana do Estado do Rio de Janeiro denominada Baixada Fluminense. No bairro vivem 18.951 habitantes, distribuídos por 5.701 domicílios (Cárcamo, 2013). O bairro possui uma infraestrutura com habitações precárias e problemas de saneamento, acesso a transportes, saúde, educação e boa parte da sua economia ainda se encontra voltada para a atividade de catação, comercialização e recuperação de materiais recicláveis, em que muitas crianças estão inseridas. O bairro sofre com graves problemas estruturais, como sujeira e mau cheiro, ocasionados pelos depósitos clandestinos. Como quase todas as comunidades periféricas do Rio de Janeiro, a comunidade sofre com a violência e falta de segurança proporcionada pelo tráfico de drogas. Há uma grande incidência de dependência química entre jovens e adultos.

A comunidade Quatro Rodas ocupa o terreno mais próximo da rampa (local onde os caminhões despejavam os materiais e resíduos quando era um aterro sanitário) de depósito do Aterro Metropolitano do Jardim Gramacho, onde grandes quantidades de lixo ainda permanecem e são depositadas, agora de forma ilegal. Estima-se que existam cerca de 100 moradias construídas, na sua maioria, por materiais como madeira, lata, papelão e algumas delas em alvenaria, mas sem rede de água potável e esgoto. O lixo ocupa quase todos os espaços da comunidade como um manto nas ruas, entulhados enquanto recicláveis nos cantos das casas e empilhados em sacos nas muretas.

O fechamento do aterro sanitário, em 2012, aumentou a segregação social e afetou diretamente o trabalho e geração de renda das famílias que passaram a ser inteiramente dependentes de programas de assistência social como o "Bolsa família", ou ainda de atividades ilegais de catação. É baixa a participação neste programa social devido às "exigências mínimas do próprio programa, que contrastam com a realidade do bairro" (Uglione, 2018, p. 1603). O baixo número de crianças matriculadas em escolas e o número elevado de adultos que não possuem documento de identificação agravam o acesso aos programas assistenciais governamentais. É comum ver muitas crianças nas ruas, no campo de futebol, próximo da rampa ou nos quintais das casas ainda realizando atividades de catação de recicláveis.

\section{O PRojeto de inVestigação-aÇão “Olhares do Gramacho": um relato de Campo}

A plataforma de desenvolvimento social e pesquisa "Eyes of the street" ${ }^{2}$ (Olhares da rua) foi criada em 2015 com a proposta de desenvolver oficinas lúdicas e artísticas que utilizam a fotografia como elemento de literacia visual, especialmente com crianças e jovens. O projeto possui seu foco na investigação-ação visual colaborativa ao colocar seus participantes como narradores visuais de suas próprias histórias. A primeira edição do projeto "Eyes of the street" foi realizada em maio de $2016 \mathrm{com}$ crianças e jovens dos bairros periféricos do Arruda e Santo Amaro, no Recife. Em julho de 2016 o projeto desenvolveu oficinas de fotografia participativa com mulheres e mães, de etnia

\footnotetext{
${ }^{2}$ Mais informações disponíveis em https://www.eyesofthestreet.org
} 
felupe, das tabancas de Suzana e Varela, na Guiné-Bissau, com o apoio da organização não governamental Voluntariado Internacional para o Desenvolvimento Africano (VIDA) (Meirinho \& Januário, 2018) e que culminaram em diversas exposições fotográficas na Guiné-Bissau, Portugal e Brasil.

Em 2017 a plataforma social "Eyes of the street" iniciou os primeiros contatos com a ONG Resgate da Infância Social (Riso) ${ }^{3}$, e a produtora Mairarêt, para a realização do projeto Olhares do Gramacho. A ação foi financiada a partir de uma campanha de financiamento colaborativo (crowdfunding) intitulada "Photography for sustainable capacity building" (Fotografia para construção de capacidades sustentáveis). Em 56 dias de campanha pela plataforma digital Crowdfunder ${ }^{5}$ foi angariado um montante de $£ 2.590,00$ (equivalente a $\mathrm{R} \$ 11.500,00$, na altura), doado por 34 apoiadores, na sua maioria europeus e brasileiros. Todo o recurso financeiro foi aplicado em logística de transporte, remuneração da equipe de produção, educadores sociais e jovens monitores residentes no Jardim Gramacho, bem como na compra de materiais para as oficinas e para a exposição. As 13 câmaras fotográficas utilizadas foram doadas por apoiadores do projeto, através de ações de mobilização nas redes sociais durante o ano de 2018.

As oficinas iniciaram no dia 5 de novembro de 2018 e foram realizadas na sede da Associação Humanitária Casa Amarela, que atua desde 2005 no Jardim Gramacho. Durante seis tardes seguidas, as 16 crianças e adolescentes, com idades entre quatro a 15 anos, estiveram nos encontros do projeto que culminou na exposição fotográfica "Olhares do Gramacho", no sábado, 10 de novembro.

Durante os seis dias foram introduzidas discussões e capacitações técnicas em fotografia, através de dinâmicas lúdicas. Todas as saídas fotográficas pela comunidade Quatro Rodas foram realizadas em duplas, sugerindo que fotografassem o convívio do bairro e aquilo que para cada um fosse de grande importância. No final de cada dia era reservado um momento para a aplicação da etapa da metodologia photovoice (Wang \& Burris), que consistia em projetar e discutir com o grupo as fotografias produzidas ( $\mathrm{Pa}$ libroda et al., 2009). Surgiam nas imagens questões como afetos, personagens, hábitos e práticas comunitárias, identificação e autorrepresentação, através de selfies, espaços, territórios lúdicos e de brincadeiras, e relações com objetos descartados ou reutilizados pela comunidade. O consumo e descarte foi tema de conversas diárias com os participantes, devido à importância que davam às suas produções visuais e aos debates. Este tópico nos permitiu levantar questionamentos e reflexões com o grupo em relação ao consumo, o desperdício material e descarte social e humano, bem como debates em torno do tipo de acesso a estes bens, enquanto receptores dos produtos descartados, por serem residentes de uma área de aterro sanitário e filhos de antigos catadores de lixo.

Para finalizar a intervenção do projeto, foi realizada a escolha das fotografias e montagem de uma exposição final no muro externo da Associação Humanitária Casa Amarela, no centro da comunidade Quatro Rodas. Cada criança e adolescente escolheu duas fotos, que foram impressas em papel fotográfico e expostas em um varal na rua.

\footnotetext{
${ }^{3}$ Mais informações disponíveis em www.ongriso.com.br

${ }^{4}$ Mais informações disponíveis em www.mairareprodutora.com

${ }_{5}^{5}$ Mais informações disponíveis em https://www.crowdfunder.co.uk/photography-and-sustainable-capacity-building
} 


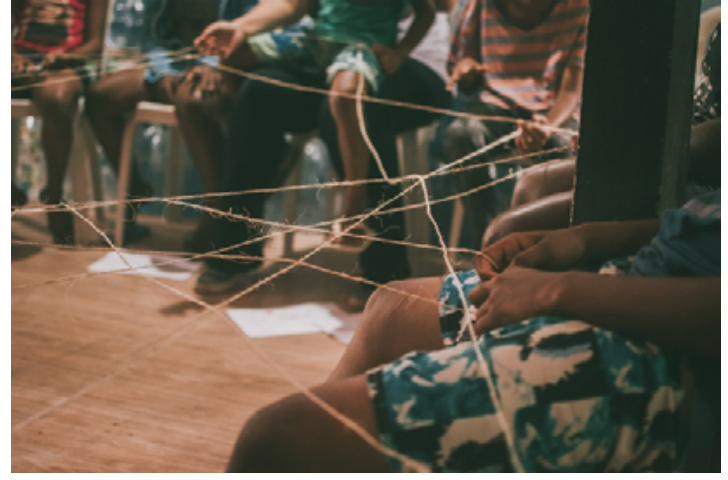

Figura 1: Dinâmicas lúdicas realizadas nas oficina do projeto "Olhares do Gramacho"

Créditos: Andressa Milanez

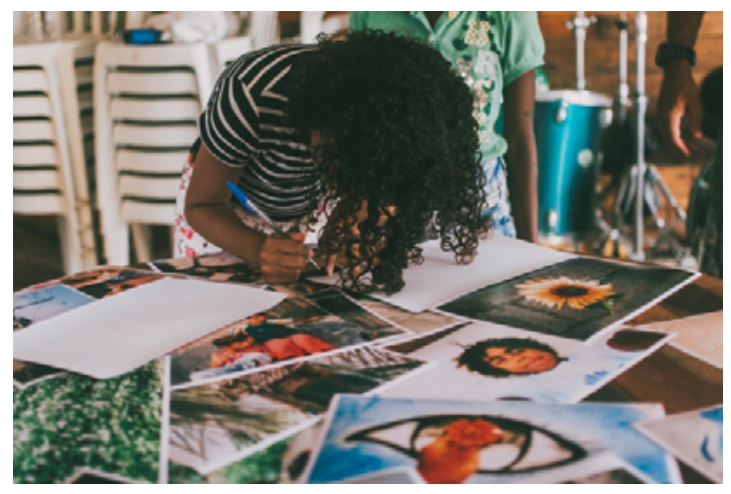

Figura 3: Escolha das fotografias para exposição Créditos: Andressa Milanez

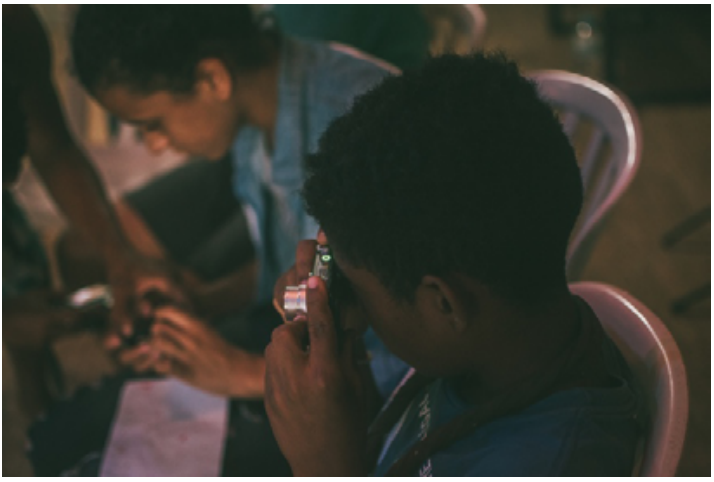

Figura 2: Crianças e jovens em seus primeiros contatos com o equipamento fotográfico utilizado

Créditos: Andressa Milanez

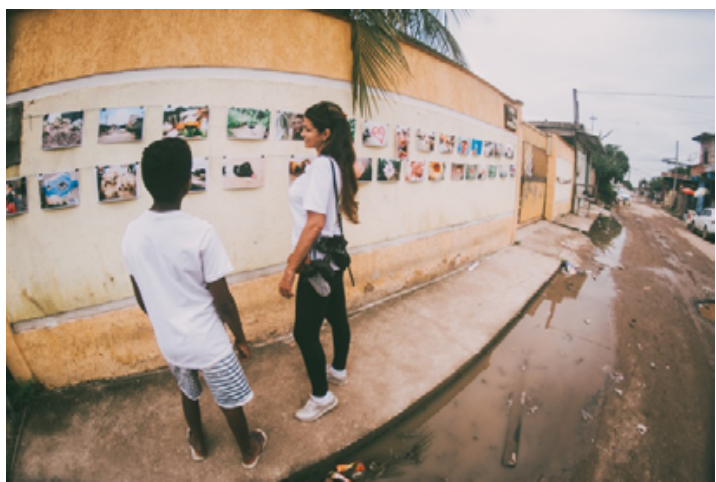

Figura 4: Exposição final realizada no muro da Casa Amarela

Créditos: Andressa Milanez

\section{OLHARES SOBRE O DESCARTE: A CONSTRUÇÃO DOS SIGNIFICADOS CONFERIDOS AO LIXO}

Diversos foram os temas e fotografias produzidas pelas crianças e jovens durante o projeto "Olhares do Gramacho", o que daria inúmeras abordagens e recortes analíticos para esta investigação sob a égide da aplicação do método photovoice (Ewald, 2001; Wilson et al., 2007). A temática escolhida para este artigo passa pela frequência das conversas com os participantes durante as oficinas e também assunto cotidiano na comunidade Quatro Rodas: a relação de descarte de objetos de consumo encontrados no lixo e despejados no Jardim Gramacho. Todos os dias, através das saídas fotográficas pela comunidade, cruzávamos com amontoados de lixo, encontradas nas imagens produzidas pelas câmaras dos jovens.

As crianças e adolescentes são reconhecidos em diversos estudos sobre consumo como participantes-chave e ativos nas estratégias de aquisição de bens de consumo como brinquedos, tecnologia, roupas, entre outros objetos que as conectam a um status simbólico de estilo e pertencimento do consumo tradicional. A infância pode ser 
percebida como cada vez mais imersa em uma sociedade em que você é aquilo que você compra (Klein, 2001). No rastro da Naomi Klein, outras publicações discutem a cultura de consumo infantil e consideram as crianças em um mundo essencialmente comercial, sendo assim percebidas como consumidores prematuros, ingênuos e indefesos. Não pretendemos entrar aqui no debate que Buckingham (2012) levanta em torno das estratégias de marketing direcionadas a uma criança-consumidora, ou discutir a possibilidade das crianças serem os sujeitos ativos e competentes no consumo que vai na contramão da concepção de indivíduos inocentes e impotentes.

No Jardim Gramacho as crianças e adolescentes vivenciam os mesmos modelos e contextos de consumo (Miller, 1995), que se diferenciam na aquisição de bens e serviços e que se tornam "uma prática no mundo e a forma na qual construímos o entendimento de nós mesmos no mundo" (Miller, 1995, p. 30). As crianças apresentam de forma clara a preocupação de estarem inseridas na cultura do consumo quando mostram conhecerem todas as marcas e produtos que lhes interessam, ao mesmo tempo que muitos dos objetos que adquirem são resultantes do descarte e do ato de "jogar no lixo", o que as coloca à margem do ambiente formal e tradicional de consumo. Para este grupo de crianças, brinquedos, acessórios, roupas e objetos são novamente configurados na situação original de utilização, mesmo sendo coisas que a "sociedade" da aquisição quis se livrar e substituir (Bauman, 2005).

Os jovens que participaram do projeto "Olhares do Gramacho" compreendem claramente o sistema de abundância e substituição de algo que não tem mais utilidade, está velho ou danificado pela necessidade de algo novo para os consumidores com acesso econômico. Suas fotografias de objetos descartados deflagram a consciência de que o acesso aos bens vem da coexistência deles com o lixo e descrevem com muita propriedade e espontaneidade que se sentem os receptáculos humanos de tudo aquilo que não serve para ser utilizado por aqueles que estão fora da comunidade, nos centros urbanos da cidade do Rio de Janeiro, em seu complexo sistema de desigualdade.

A maioria das crianças participantes do projeto sai pouco do contexto comunitário, e apenas entra em contato com outras realidades ou indivíduos quando vai à escola ou ao centro de Duque de Caxias, seguindo a mesma metáfora do protótipo territorial dos excluídos. Estes são os momentos em que entram em contato e passam a ser afetadas e impactadas pelos mesmos significados simbólicos, estrutura cultural e códigos do consumo, seja nos diálogos familiares, ambientes escolares ou de contato com os produtos mediáticos, especialmente televisivos, pois o acesso à internet e à tecnologia ainda é muito restrito.

As crianças e adolescentes têm consciência que são repositório de descarte de tudo que se torna obsoleto para a cultura de consumo, garantindo a percepção de que estão fora de um lugar de privilégio de aquisição de bens, onde grande parte da população quer estar. O lixo representa o local de rejeição humana e de objetos, que reflete diretamente na baixa autoestima, associada à pobreza e à exclusão. Estes se encontram e se reconhecem a partir do que Goffman (1988) compreende de identidade social deteriorada de indivíduos estigmatizados, considerados estranhos. De pessoas inferiorizadas, engatadas na lógica do consumo do lixo. 
Mesmo com diversos problemas de saneamento, o consumo lúdico do brincar na infância é representado nas fotografias em um ambiente precário e inóspito, com existência de doenças decorrentes do lixo depositado pelos mais de 30 anos no local. Tal perspectiva de consumo pode ser visto na Figura 5 da adolescente Cassiane ${ }^{6}$, de 12 anos, que fotografou adolescentes tomando banho e saltando na lagoa de tratamento do antigo aterro sanitário. Seus espaços lúdicos de jogos e brincadeiras são cheios de lixo e dejetos humano e as brincadeiras ocorrem ao ver crianças descalças correndo em meio de substâncias tóxicas e um manto de lixo que cobre as ruas. O risco de contaminação por infecções intestinais é muito recorrente entre as crianças e residentes da comunidade Quatro Rodas.

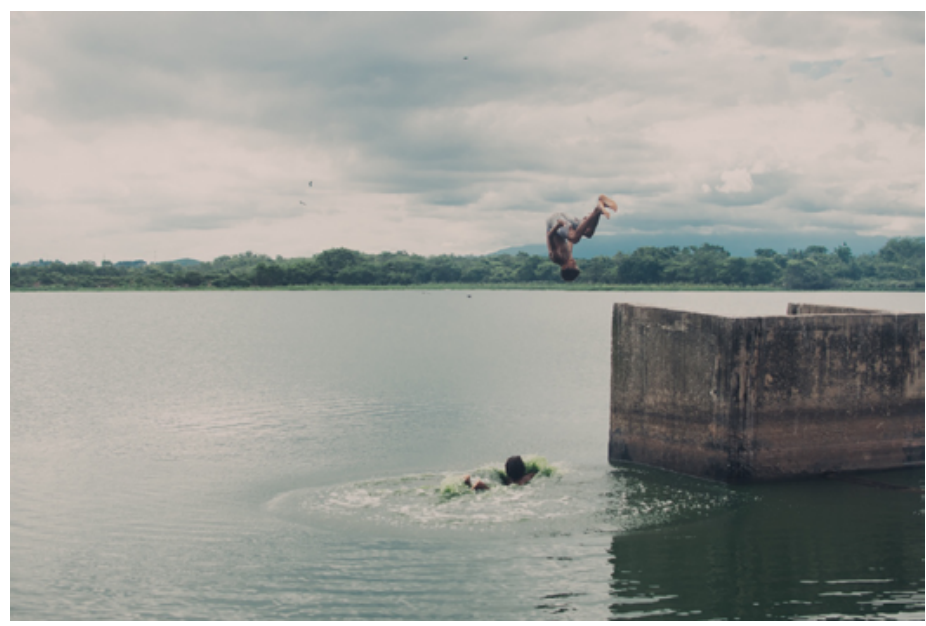

Figura 5: Fotografia de Cassiane (12 anos)

Créditos: Cassiane

A temática do brinquedo e sua representação simbólica para a infância e adolescência foi outra questão de destaque nas fotografias produzidas pelos participantes. Podemos partir da perspectiva de que os brinquedos, geralmente, são objetos do universo infantil que dão vida ao brincar, ao lúdico (Brougére, 2008). É possível perceber que por meio dele a criança se apropria do mundo real, se relaciona e se integra culturalmente, sendo um objeto de muito valor na infância, dentro do mundo dos bens (Douglas \& Isherwood, 2013). Contudo, os brinquedos no Gramacho não se configuram apenas pela representação da fábula ou fantasia associadas aos bichinhos, personagens famosos, de desenhos animados ou super-heróis. A situação imaginária em que a criança assume papéis e comportamentos na fabulação lúdica do brincar é feita pelas crianças e jovens do Jardim Gramacho através dos brinquedos danificados. Este argumento é visto na $\mathrm{Fi}$ gura 6, do adolescente Cássio, de 12 anos, que fotografou uma boneca enterrada na rua, só com a cabeça de fora.

\footnotetext{
${ }^{6}$ Neste artigo foram usados pseudónimos para todos os participantes com o intuito de confidencialidade e com a finalidade de proteger a sua privacidade (Marshall \& Shepard, 2006).
} 


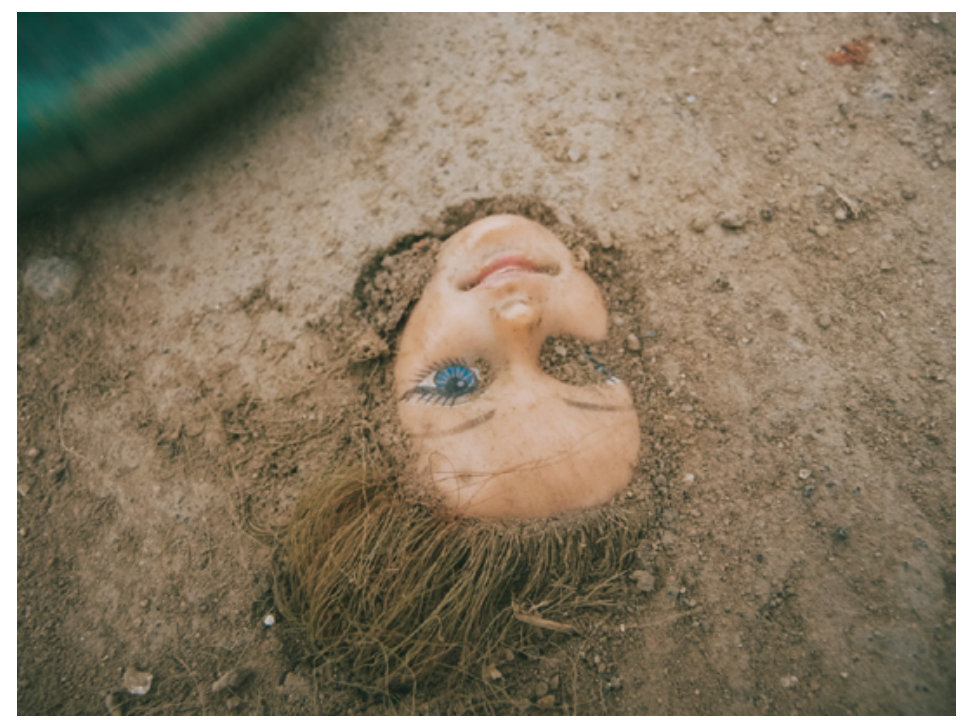

Figura 6: Fotografia de Cássio (12 anos)

Créditos: Cassio

É comum brincar com bonecas descartadas e brinquedos quebrados. O pensamento sobre a posse dos bens retirados do lixo é de que existe a possibilidade de posse de um determinado objeto, já que em alguns casos, como brinquedos, são percebidos como símbolos de prestígio (Goffman, 1988). Para Brougére (2008), entre as funções sociais do brinquedo destaca-se a de suporte de relação afetiva. Isto é, sua posse inclui um valor de prestígio que pouco a pouco vai se construindo a partir da convergência entre a imagem portadora de valores simbólicos e significação social e a função social do brinquedo. A reação de especificidade com o brinquedo para as crianças do Jardim Gramacho continua na experiência da posse, que insere a criança no universo do consumo, mas de forma reciclada no que toca ao uso destes objetos. As crianças conferem significados aos brinquedos descartados, ganhando novas relações lógicas em que passam a ser um espelho fiel, não da realidade exterior, mas da realidade cultural e simbólica da criança da comunidade, em conexão com toda a cultura de consumo e mediática que passa a ter acesso. Ver como estes brinquedos são reapropriados e descartados na rua, às vezes sem muito apego, é se confrontar com a imagem e o mundo cultural deste grupo de crianças e adolescentes.

Muitos jovens, ao verem as imagens de objetos que foram jogados no lixo e reaproveitados em suas fotografias, informaram que sempre foi comum terem uma infância com brinquedos, móveis, roupas e acessórios retirados do lixo, sendo reutilizados sem questionar a dignidade do acesso a estes bens. Tal posse denota mais do que meros objetos: representa um código social de inclusão em uma sociedade de consumo, invertida. Ao mesmo tempo que recebem os produtos descartados cotidianamente, as crianças e adolescentes estão inseridos no sistema de consumo em que a infância é um poderoso alvo da engrenagem mediática de consumo (Souza, 2016), quando reconhecem esses objetos a partir de suas marcas e associações aos anúncios publicitários. 
Por fim, a última temática de análise neste trabalho se dá em relação às imagens produzidas pelos participantes dos utensílios da casa e sua extensão para a rua como códigos distintos de significação. Muitos objetos que compõem o preenchimento da casa como eletrodomésticos, móveis, aparelhos eletrônicos obsoletos e esquecidos são apresentados no ambiente da rua como extensão da casa e representam o ambiente de descarte do Jardim Gramacho, como pode ser visto na Figura 7. A fotografia do sofá na rua, do adolescente Anderson (14 anos), representa o objeto enquanto relíquia guardada por uma família, que passa a ser de uso coletivo, porém inserido em uma nova ordem e uma nova significação como parte do acervo da rua. O ritual de consumo de bens de uma casa, bem como a arrumação e organização do seu bem, seguem a mesma lógica do descarte. Muitos objetos entram para casa e os moradores passam a possuir estantes para guardá-los como prémios decorativos encontrados no lixo, que ganham uma nova vida na ornamentação do espaço doméstico. Mesmo com a perda da funcionalidade, por sua vez, em alguns casos, são conferidos outros usos em um novo arranjo estético e decorativo, ao invés de sua funcionalidade.

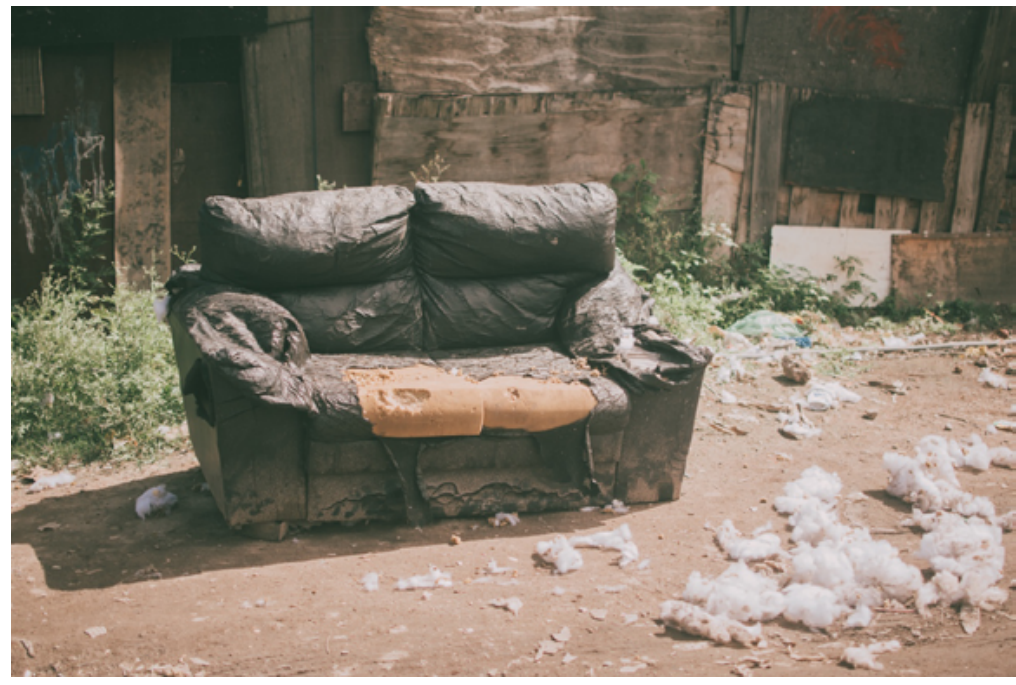

Figura 7: Fotografia de Anderson (14 anos)

Créditos: Anderson

O apego aos bens materiais por parte das crianças e adolescentes é relativo à importância que esses objetos possuem dentro de um código de consumo externo, ou nas condições de alguns objetos, em fábula perversa onde tudo se encontra, mas ao mesmo tempo já é danificado. Como o modelo de consumo contemporâneo se concentra na desvalorização imediata de objetos antigos que gera uma insatisfação com a identidade adquirida nessa cultura. A importância está no próprio objeto de consumo e no sistema de significação atribuídos pelas crianças e adolescentes às relações sociais e culturais e não à aquisição de valores (Douglas \& Isherwood, 2013).

O recorte analítico mostra que a hierarquização social não provém do valor econômico dos bens de consumo, mas sim dos significados de posse em uma espécie de 
"acordo coletivo" de representações. No Jardim Gramacho os objetos são resignificados em uma cadeia de valor que comummente atribui importância a coisas que podem gerar lucro. Nesta ótica, até o lixo deve ser transformado em valor financeiro, devido à possibilidade de renovação da matéria prima através da reciclagem.

\section{CONSIDERAÇÕES FINAIS}

Este artigo parte de um recorte de análise de um projeto de investigação-ação visual que possui a intenção de mobilização social para um desenvolvimento comunitário, com enfoque na infância e adolescência, aplicando os conceitos e estratégias do método photovoice (Wang \& Burris, 1997). A imagem fotográfica foi concebida e utilizada como uma ferramenta de documentação e mobilização social ao mesmo tempo que apresentou relatos visuais e discussões com o grupo pesquisado a partir do recorte em torno da lógica de consumo e das relações com o lixo e o ambiente de descarte contemporâneo (Uglione, 2018). A fotografia demonstrou ser uma ferramenta metodológica altamente flexível que nos possibilitou atravessar barreiras de significação e representação. A imagem assumiu nesta investigação um papel de agente catalisador de diálogos e reflexões em torno das preocupações deste grupo de crianças e adolescentes, auxiliando num processo analítico de preocupações em torno das crianças residentes nos lixões e seu contexto de infância a partir de polos antagónicos e excludentes que os colocam como agentes protagonistas desta pesquisa.

Percebemos, a partir deste recorte de imagens analisadas que a infância transcende o potencial da sociedade de proteção de crianças e adolescentes dentro e fora dos lixões. É um complexo e constrangedor contexto de ser observado e analisado, especialmente pelos estranhamentos que convoca e provoca sobre esta nova estética de representação por aqueles que convivem neste ambiente.

O trabalho apresenta a compreensão em torno do consumo de objetos descartáveis para as crianças e adolescentes, e passa por um processo de objetificação. Este deve ser entendido através da dialética de desigualdade de aquisição e acesso condizentes com as contradições culturais em que estão inseridos. Concordamos com o argumento de Douglas e Isherwood (2013), que compreendem o consumo como um processo comunicativo de afirmação de valores, práticas e rituais sociais, servindo como formas de inclusão e exclusão das crianças nos círculos sociais. Para além dos valores utilitários, os bens descartados e encontrados no lixo participam da constituição de relações sociais e de identidades, de pertencimento ou distanciamento da sociedade de consumo. Eles estão fora da atividade cotidiana de consumir, que os coloca excluídos do processo de significação identitária de participação social.

A inserção das crianças e adolescentes no universo de consumo representa uma infância que convive com mercadorias descartadas no lixo, da renda de materiais acumulados em entulhos nos jardins das casas pela família, como geração de renda, ou até mesmo como um grupo social prioritário receptor da doação de entidades e pessoas que vão até o local e entregam o que já não utilizam ou necessita ser colocado no "lixo", 
ativando um novo ciclo de consumo chamado de sustentabilidade ou atitudes de compaixão e solidariedade com os grupos sociais mais necessitados.

\section{AgradeCimentos}

O presente trabalho foi realizado com apoio da Coordenação de Aperfeiçoamento de Pessoal de Nível Superior - Brasil (CAPES) - Código de Financiamento oor.

\section{REFERÊNCIAS}

Barthes, R. (1984). A câmara clara: nota sobre a fotografia. Rio de Janeiro: Nova Fronteira.

Bastos, V P. (2007). Na rota do lixo: da casa ao catador o primeiro trajeto da cadeia industrial de reciclagem. Caderno de Comunicações do XII Congresso Brasileiro de Assistentes Sociais. Foz do Iguaçu: CFESS.

Baudrillard, J. (1995). A sociedade de consumo. Lisboa: Edições 70.

Bauman, Z. (2005). Vidas desperdiçadas. Rio de Janeiro: Jorge Zahar.

Brougére, G. (2008). Brinquedo e cultura (7. ${ }^{a}$ ed.). São Paulo: Cortez.

Buckingham, D. (2012). Repensando a criança-consumidora: novas práticas, novos paradigmas. Comunicação, Mídia e Consumo, 9(25), 43-72. https://doi.org/10.18568/cmc.vgi25.311

Cárcamo M. I. (2013). Configuração territorial e problemas de saúde e ambiente em uma periferia metropolitana: o caso do bairro Jardim Gramacho - Duque de Caxias. Dissertação de Mestrado, Escola Nacional de Saúde Pública Sergio Arouca, FIOCRUZ, Rio de Janeiro, Brasil. Retirado de https://www.arca.fiocruz.br/ handle/icict/24535

Cárcamo, M. I. C., de Oliveira, R. M. \& da Cunha, M. B. (2018). Configuração socioespacial e problemas de saneamento em uma periferia metropolitana: o caso do bairro Jardim Gramacho-Duque de Caxias. Ágora, 20(2), 77-89. https://doi.org/10.17058/agora.v20i2.12297

Clark, A. (2007). Views from inside the shed: young children's perspectives of the outdoor environment. Education, 35(4), 349-363. https://doi.org/10.1080/03004270701602483

Daldry, S. (Realizador). (2014). Trash - a esperança vem do lixo [Filme]. Brasil/Reino Unido: Universal Pictures.

Decreto $n^{\circ}$ 99.710, de 21 de novembro, República do Brasil.

Douglas, M \& Isherwood, B. (2013). O mundo dos bens: para uma antropologia do consumo. Rio de Janeiro: Editora UFR.

Ewald, W. (2001). I wanna take me a picture: teaching photography and writing to children. Boston: Beacon Press.

Goffman, E. (1998). Estigma: notas sobre a manipulação da identidade deteriorada (4. ${ }^{a}$ ed). São Paulo: LTC.

Greene, S \& Hogan, D. (Eds.) (2005). Researching children's experience: approaches and methods. Londres: SAGE.

IBASE, Instituto Brasileiro de Análises Sociais e Econômicas. (2019). Diagnóstico social: bairro Jardim Gramacho. Retirado de https://ibase.br/pt/midiateca/publicacoes/publicacoes/ 
Khanlou, N. \& Peter, E. (2005). Participatory action research: considerations for ethical review. Social Science Q Medicine, 6o(10), 2333-2340. https://doi.org/10.1016/j.socscimed.2004.10.004

Klein, N. (2001). No Logo. Londres: Flamingo.

Lewis, A. \& Lindsay, G. (2000). Researching children's perspectives. Philadelphia: Buckingham, Open University Press.

Lundy, L. \& McEvoy, L. (2012). Childhood, the United Nations Convention on the Rights of the Child, and research: what constitutes a "rights-based" approach? In M. Freeman (Ed.), Law and childhood studies: current legal issues volume 14 (pp. 75-91) Oxford: Oxford University Press.

Lust, D. (2013). When a child has a disability: exploring the experience of adolescent siblings through photovoice. Tese de Doutoramento, Universidade de Toledo, Toledo, EUA.

Marshall, A. \& Shepard, B. (2006) Youth on the margins: qualitative research with adolescent groups. In B. Lead- Beater; E.B.B.C. Benoit; E. Jansson; A. Marshall \& T. Riecken (Orgs.), Ethical issues in communitybased re- search with children and youth (pp. 140-156). Toronto: University of Toronto Press.

Mcintyre, A. \& Thusi, T. (2003). Children and youth in Sierra Leone's peace-building process. African Security Review, 12(2), 73-80. https://doi.org/10.1080/10246029.2003.9627222

Meirinho, D. (2016). Olhares em foco. Fotografia participativa e empoderamento juvenil. Covilhã: LabCom.IFP.

Meirinho, D. \& Januário, S. B. (2018). Fotografia participativa e relações de gênero: uma experiência visual com mulheres guineenses. Fronteiras-estudos midiáticos, 20(2), 252-264. https://doi.org/10.4013/ fem.2018.202.10

Miller, D. (1995). Consumption as the vanguard of history: a polemic by way of an introduction. In D. Miller (Ed.), Acknowledging consumption (a review of new studies) (pp. 140-156). Londres; Nova lorque: Routledge.

Palibroda, B., Krieg, B., Murdock, L. \& Havelock, J. (2009). A practical guide to photovoice: sharing pictures, telling stories and changing communities. Retirado de http://www.pwhce.ca/photovoice/pdf/Photovoice Manual.pdf

Pereira, R., Gomes, L. \& Silva, C. F. S. (2018). A infância no fio da navalha: construção teórica como agir ético. ETD-Educação Temática Digital, 20(3), 761-780. https://doi.org/10.20396/etd.v20i3.8649227

Prado, M. (Realizador). (2015). Estamira [Filme]. Brasil.

Sealy, M. (2019). Decolonizing the camera: photography in racial time. Londres: Lawrence e Wishart.

Sinclair, R. (2004). Participation in practice: making it meaningful, effective and sustainable. Children and Society, 18(2), 106-118. https://doi.org/10.1002/chi.817

Sontag, S. (1986). Sobre fotografia. São Paulo: Publicações Dom Quixote.

Souza, S J. (2016). Criança e consumo: dez anos de transformação. São Paulo: Instituto Alana.

Spielman, J. (2001). The family photography project: we will just read what the pictures tell us. The Reading Teacher, 54(2), 762-770. Retirado de https://www.jstor.org/stable/20204991?seq=1

Taylor, C. (1994). The politics of recognition. In C. Taylor \& A. Gutmann (Eds.), Multiculturalism: examining the politics of recognition (pp. 25-74). Princeton, NJ: Princeton University Press. 
Uglione, P. (2018). Crianças e lixões: infâncias e cidades por vir. In M. Alcántara; M. G. Monteiro \& F. S. López (Eds.), Estudios Sociales: memoria del 56. ${ }^{\circ}$ Congreso Internacional de Americanistas (pp. 1599-1607). Salamanca: Ediciones Universidad de Salamanca.

Walker, L., Jardim, J. \& Harley, K. (Realizadores). (2010). Lixo extraordinário [Filme]. Reino Unido/Brasil.

Wang, C. C. \& Burris, M. A. (1997). Photovoice: concept, methodology, and use for participatory needs assessment. Health Education and Behavior, 24, 369-387. https://doi.org/10.1177/109019819702400309

Wilson, N., Dasho, S., Martin, A.C., Wallerstein, N., Wang, C.C. \& Minkler, M. (2007). Engaging young adolescents in social action through photovoice: the Youth Empowerment Strategies (YES!) project. Journal of Early Adolescence, 27(2), 241-261. https://doi.org/10.1177/0272431606294834

Woodlrych, R. (2004). Empowering images: using photovoice with tenants with special needs. Housing, Care and Support, 7(1), 31-36. https://doi.org/10.1108/14608790200400007

\section{NOTA BIOGRÁFICA}

Doutor em Ciências da Comunicação pela Faculdade de Ciências Sociais e Humanas da Universidade NOVA de Lisboa, professor no Departamento de Comunicação Social da Universidade Federal do Rio Grande do Norte (UFRN), Brasil e professor e pesquisador do Programa de Pós-Graduação em Estudos da Mídia (PPgEM/UFRN)

ORCID: https://orcid.org/oooo-0002-4658-5556

Email: danielmeirinho@hotmail.com

Morada: Rua Correa Dutra, 128 - Apt. 204, Catete, Rio de Janeiro - RJ, Brasil CEP $22210-050$

* Submissão: 18/12/2019

* Aceitação: 19/04/2020 